\title{
ERA UMA VEZ... OS \\ CONTOS DE FADAS COMO \\ RECURSOTERAPÊUTICO COM \\ CRIANÇAS HOSPITALIZADAS
}

\author{
Maria das Graças Ferreira Gonçalves*, Ana Aparecida Nascimento Martinelli Braga** \\ Autora correspondente: Maria das Graças Ferreira Gonçalves mgracasgoncalves.psi@gmail.com \\ * Pós-graduanda do Curso de Especialização avançada em Neuropsicologia - UFBA. Graduação em Psicologia \\ pela Escola Bahiana de Medicina e Saúde Pública (2013). \\ ** Psicanalista, Mestre em Comunicação e Cultura Contemporâneas (UFBA). Especialista em Psicologia Clínica \\ (PUC/RJ). Graduada em Psicologia (UFBA). Docente da Escola Bahiana de Medicina e Saúde Pública.
}

\section{Resumo}

A hospitalização é um dos momentos mais impactantes na vida de uma criança, pois interfere na sua qualidade de vida como um todo. Os contos de fadas podem ser usados como recurso terapêutico, pelo psicólogo hospitalar, por fazer parte do universo infantil, ser importante para o seu desenvolvimento, e auxiliar no processo de elaboração psíquica. Esta pesquisa bibliográfica tem como principal aporte teórico a Psicanálise. Pretende-se com o objetivo geral compreender como os contos de fadas, utilizados como recurso terapêutico, podem auxiliar as crianças no enfrentamento do período de internação hospitalar, sendo os específicos: estudar a função terapêutica do conto; conhecer os efeitos do impacto que o conto exerce sobre a criança; assim como entender como se dá a relação psicólogo-conto-criança. As considerações conclusivas apontam que o conto de fadas não é a única ferramenta de intervenção a ser utilizada com crianças no enfrentamento durante o período de internação hospitalar, entretanto pode ser considerado como um importante instrumento de trabalho pela sua eficácia como função terapêutica.

Palavras-chave: Psicanálise; Criança hospitalizada; Psicólogo hospitalar; Contos de fadas. 


\title{
ONCE UPON A TIME... FAIRY TALES AS A THERAPEUTIC RESOURCE WITH HOSPITALIZED CHILDREN
}

\begin{abstract}
The hospitalization is one of the most striking moments in a child 's life as it interferes in their life quality as a whole. The fairy tales can be used as a therapeutic resource, by hospital psychologists, as these tales are part of the infant universe, important for children's development and help in their psychic elaboration process. This bibliographic research has psychoanalysis as its principal theoretical subsidy. The main objective is to comprehend how the fairy tales, used as a therapeutic resource can help children in their confrontation during the hospital internment. The specific objectives are: to study the therapeutic function of the tale, to know the effects that the tales have on a child, as well as to understand how the relationship psychologist-talechild comes to be. The conclusive considerations indicate that the fairy tales are not the only instrument of intervention to be used with children in their confrontation during the hospital internment process, although it can be considered as an important instrument due to its efficacy while therapeutic function.
\end{abstract}

Keywords: Psychoanalysis; Hospitalized child; Hospital psychologist; Fairy tales.

\section{INTRODUÇÃO}

\section{ERA UMA VEZ...}

É assim que geralmente os contos de fadas iniciam. Constituídos fora de uma verdadeira noção de tempo e espaço, pode-se dizer que esses contos são atemporais. Eles desafiaram o tempo, e chegaram até os dias atuais.

Segundo Kehl(1) "a capacidade de sobrevivência dos melhores contos [...] consiste em seu poder de simbolizar e "resolver" os conflitos psíquicos inconscientes que ainda dizem respeito às crianças de hoje" (p.16).

A partir do advento da Psicanálise, no final do século XIX, esse tipo de literatura - de ficção - passou a ser estudado de forma mais sistematizada. Já a sua utilização terapêutica, se deu um pouco mais tarde. ${ }^{(2,3)}$ Diante disso, Gutfreind ${ }^{(4)}$ considera a Psicanálise como pioneira em se ocupar das investigações sobre esses contos, e enfatiza a importância de reconhecê-los como instigadores de nossa atividade mental.

A obra de Freud tornou-se referência para os avanços dos estudos sobre o tema, na medida em que "os contos de fadas" se encontram presentes ao longo dos seus escritos. Assim, Freud abriu um importante campo de pesquisa, desdobrado por alguns dos seus seguidores, tais como Ferenczi e Melanie Klein, e por estudiosos contemporâneos, como, por exemplo, Bruno Bettelheim, entre outros. (4)

No decorrer da história, os contos fadas despertaram a atenção de psicólogos e psicanalistas, 
dos quais se distingue o já citado psicólogo infantil Bruno Bettelheim, por ser o primeiro a analisar e registrar - do ponto de vista psicanalítico -, as ideias sobre a importância dessas histórias na vida das crianças, com sua obra clássica: A Psicanálise dos Contos de Fadas (1976). ${ }^{(4,5)}$

Nas últimas décadas, os psicólogos têm se utilizado das histórias de fadas como instrumento terapêutico no trabalho com crianças, tanto quanto de adolescentes e adultos, na elaboração de suas questões, através dos enredos, personagens, e conteúdos apresentados pelas próprias histórias.(5,6)

Assim, discorre-se este estudo a partir da seguinte questão central: Qual a importância da utilização dos contos de fadas como recurso terapêutico com crianças hospitalizadas? A condição de hospitalização infantil é considerada como um momento muito impactante para uma criança, pois interfere na sua qualidade de vida como um todo.(7,8) Diante disso, enfatizou-se a busca de conceitos e formas que a abordagem psicanalítica através de seus estudos sobre essa "arte literária", o conto de fadas, como Bettelheim ${ }^{(9)}$ também a considera - pode disponibilizar como ferramenta de intervenção para ser utilizada, pelo psicólogo hospitalar, no contexto de sua atuação: o hospital. Diante do exposto, apresenta-se, como objetivo geral, compreender como os contos de fadas, utilizados como recurso terapêutico, podem auxiliar as crianças no enfrentamento do período de internação hospitalar.

Desse modo, este trabalho se justifica pela possibilidade de trazer à tona um tema de estudo relevante para a atuação do psicólogo através do uso dos contos de fadas como ferramenta de trabalho, considerado como um desafio diante das limitações de tempo e espaço do setting hospitalar. Nesse sentido, considera-se o papel do psicólogo de fundamental importância por se tratar do profissional que pode utilizar-se desse instrumento como mediador nesse contexto.

Procurou-se organizar este trabalho em torno de três principais eixos: Inicialmente dá-se ênfase em argumentar sobre o conto de fadas e a sua relação com a teoria psicanalítica, a fim de apresentá-lo de forma mais sistematizada. No segundo momento, fala-se sobre a criança hospitalizada e o impacto causado pela internação. E por fim, apresenta-se uma breve história dos contos de fadas, o uso destes pelo psicólogo hospitalar e o seu significado para o mundo infantil.

No decorrer desse estudo, alguns questionamentos foram construídos, como: 1) O que faz do conto de fadas um instrumento terapêutico? 2) Como o conto atua na criança? 3) Quando e como usar o conto como ferramenta de trabalho? Estes se desdobraram em objetivos específicos e foram estabelecidos em: estudar sobre a função terapêutica do conto; conhecer os efeitos do impacto que o conto exerce sobre a criança; assim como entender como se dá a relação psicólogo-conto-criança.

\section{MÉTODO}

A pesquisa se constitui em um estudo bibliográfico, a partir da qual se utilizou de um levantamento de referências, conceitos, teorias, no âmbito da psicanálise. Assim, foram selecionados livros, referentes à temática, artigos em formato eletrônico, na Biblioteca Virtual Técnico-Científica (BVS-PSI), e nas bases de dados Scientific Eletronic Library Online (Scielo) e Literatura Latino-Americana de Ciências de Saúde (Lilacs), a partir das palavras: psicanálise, criança hospitalizada, psicólogo hospitalar e contos de fadas, e em artigos de outras revistas em formato impresso. Traçou-se um plano de leitura com anotações e fichamentos para análise e interpretação das abordagens psicanalíticas que circundam o tema em foco. Com o objetivo de enriquecer a compreensão dos conceitos, foram utilizados dicionários de língua portuguesa e de psicanálise.

A partir de então, buscou-se responder à problemática da pesquisa, aprofundando consensos e divergências, assim como recriando novas indagações.

É importante ressaltar que este trabalho teve como principal aporte teórico a Psicanálise, tendo 
em vista a mesma ser uma das abordagens que se apropria de estudos de forma mais sistematizada sobre os Contos de Fadas. Trata-se de uma pesquisa realizada e voltada para o estudo dos conceitos, bem como para a função terapêutica do conto de fadas, visando incentivar novos estudos sobre o tema, mas, principalmente, contribuir com o interesse do psicólogo hospitalar em utilizar-se desse tipo de narrativa como ferramenta de trabalho no contexto hospitalar - com crianças.

\section{O PONTO DE VISTA DA PSICANÁLISE SOBRE O CONTO}

É a partir do advento da Psicanálise, no final do século XIX, que o conto de fadas passou a ser estudado de forma mais sistematizada. Já a sua utilização terapêutica se deu um pouco mais tarde, como afirmam Velay-Vallantin(2) e Novaes Coelho. (3) Diante disso, Gutfreind ${ }^{(4)}$ considera a Psicanálise como pioneira em se ocupar das investigações sobre o conto, e enfatiza a importância de reconhecê-lo como instigador de nossa atividade mental. É o que, também, sugerem vários autores que trataram o tema, teoricamente como Guérin, ${ }^{(10)}$ e de forma mais prática e clínica, como Lafforgue, ${ }^{(11)}$ segundo o referido autor.

Guérin ${ }^{(10)}$ ao fazer uma pesquisa sobre a presença dos contos na obra de Freud, e ao referir-se à décima quarta Conferência de Introdução à Psicanálise, revelou o quanto esse teórico já havia notado acerca do poder dessas histórias, em relação a seu conteúdo, de serem capazes de simbolizar os desejos mais profundos do leitor ou do ouvinte. Nesse sentido, Gutfreind(4) confirma uma presença considerável do conto - especificamente o conto de fadas - na obra de Freud (1900, 1908, 1911, 1913a, 1913b e 1918), fato este, que surpreendeu o autor. Sendo assim, é possível admitir um registro significativo dessa forma de literatura ${ }^{1{ }_{1}}$ em seus escritos.

Literatura de ficção. O romance, a novela, o conto. [Tb. se diz apenas ficçao. Sin. ficcionismo $]^{(13)}$
Freud não se utilizou do conto como instrumento terpêutico como fazem alguns autores na contemporaneidade, por exemplo, Gutfreind, (4) Corso e Corso, ${ }^{(5)}$ Radino, ${ }^{(12)}$ entre outros, geralmente baseados na obra de Bettelheim. Todavia, foi ele que lançou um dos

pensamentos mais importantes, abarcados pelos estudiosos do assunto, podendo-se citar Pierre Lafforgue.(11) Esse pensamento "[...] se refere à presença, nos contos (e também nos mitos e na arte em geral), das representações mais arcaicas do psiquismo humano, como, por exemplo, a da devoração". ${ }^{(4)}$ (p. 148).

Nesse sentido, Guérin ${ }^{(10)}$ afirma que da mesma forma em relação aos mitos, Freud (1913) observou nos contos uma melhor maneira de entender a atividade mental. Eles se encontram no decorrer de sua obra, sendo sempre observados como fonte de "motivos humanos" - contemplados pelo conto -, como por exemplo, a esperança. (4)

De acordo com Corso e Corso, ${ }^{(5)}$ o campo das narrativas é familiar à Psicanálise. Para eles, em outras palavras, a vida se traduz em uma história, e o que falamos dela "é sempre algum tipo de ficção" (p. 21). Enfatizam que a atração pela "fantasia" começa desde cedo, na infância, e é o que sustenta a ficção. Portanto, segundo os autores, não há registro da infância sem ela - a ficção.

Ao estudar sobre a função reguladora que a "ficção"2 organiza em relação ao retorno do material "psíquico reprimido", inspirado no pensamento freudiano (1919), Guérin ${ }^{(10)}$ considera o conto como um instrumento capaz de evitar uma desordem emocional na medida em que ele pode reter 0 retorno desse material "reprimido" e "ameaçador", promovendo um processo de elaboração psíquica, evitando assim "a paralisação do pensamento"

Dessa forma, Gutfreind ${ }^{(4)}$ acredita que:

Ler ou ouvir contos pode significar, então, continuar pensando sobre nós mesmos, no momento em que entramos em contato com sentimentos e conflitos

\footnotetext{
Espaço de organização estética desses conteúdos, ela poderia funcionar como "um aparelho psíquico substituto" para administrar esse material, sobretudo em casos nos quais o aparelho original se encontre fragilizado. (p. 145-146). ${ }^{(10)}$
} 
difíceis de serem suportados e que, sem esse filtro da narrativa, poderiam paralisar nossa capacidade associativa ou ainda nos causar sintomas (p.146).

Sendo assim, o autor citado, em sua experiência clínica, relata ter encontrado inúmeras ilustrações a respeito dessas ideias, como a do caso Béatrice, "a menina triste e que

pouco se expressava sobre sua difícil situação de separação dos pais". O autor acrescenta que Béatrice, ao se apegar "[...] ao conto do Patinho Feio, de Andersen, e, depois de solicitar a mesma história muitas vezes, desenvolveu a capacidade de falar a respeito da tristeza da personagem". E assim, "Identificada e ao mesmo tempo protegida pelo patinho, pôde expressar o que sentia e, [...] pensar sobre os próprios sentimentos [...]", ou seja, "a difícil tristeza [...] de se sentir mal amada”.(4) (p. 146).

Já Lafforgue ${ }^{(11)}$ chama a atenção para o potencial que essas histórias têm a partir de sua estrutura e conteúdo, em ordenar os representantes mais "arcaicos da infância" - como já mencionava Freud (1926) -, como por exemplo, "a oralidade (fantasias de devoração), os sentimentos do vazio, de rejeição, entre outros". Diante disso, o autor afirma que a criança compara os dilemas existenciais contidos nas histórias com os seus próprios, o que resulta em uma melhor administração de suas aflições. Com essa afirmativa, Lafforgue(11) resume a função terapêutica do conto nos seguintes termos: "organizador" e "continente" (p. 146-147). Com essa colocação, aqui também se encaixa o exemplo de Béatrice, que ao identificar-se com o Patinho Feio - o personagem meio que "empresta" sua voz para o leitor -, acreditou que, se o patinho encontrou solução para o seu conflito, ela também encontraria, mesmo que fosse na fantasia pessoal, conforme Gutfreind.(4)

Entre os conceitos para entender a função terapêutica do conto, também se encontra o lúdico. Segundo Gutfreind, (4) a ludicidade acontece com o encontro entre a criança e a história. Para o autor, é se divertindo de maneira simples ou experienciando o prazer (o jeito de brincar) que a criança cresceria em sua capacidade mental, desenvolvendo "espaços psíquicos" (capacidade, conforme Winnicott, 1951 e 1971, lúdico segundo Pavlovsky, 1980), como suporte de vida imaginária, de sua capacidade criativa e de resistência às "situações traumáticas" da vida, sem perder o equilíbrio de sua saúde mental, logo, enfrentando as enfermidades.

Outro ponto interessante na literatura psicanalítica sobre os contos, e que merece destaque, é a relação entre eles (os contos) e os sonhos. Para se falar sobre o tema, pode-se dizer que ao referir-se ao artigo de 1913 - A ocorrência, em sonhos, de material oriundo de contos de fadas - Gutfreind(4) afirma que Freud reconheceu a importância dos contos populares na vida mental de seus pacientes. De acordo com o autor, ao descrever dois casos clínicos de seus pacientes, Freud confirma a "hipótese" de que os recursos e os conteúdos das histórias escutadas na infância apareciam, frequentemente, em seus sonhos.

A esse respeito, Freud(14) faz a seguinte elucidação:

\footnotetext{
Não é surpreendente descobrir que a psicanálise confirma nosso reconhecimento do lugar importante que os contos de fadas populares alcançaram na vida mental de nossos filhos. Em algumas pessoas, a rememoração de seus contos de fadas favoritos ocupa o lugar das lembranças de sua própria infância; elas transformaram esses contos em lembranças encobridoras. (p. 305).
}

Ao fazer uma leitura da Interpretação dos Sonhos, Freud (1900), Guérin, ${ }^{(10)}$ por exemplo, salientou que o conto pode ser "um local de estoque" de algum problema não solucionado, de onde se pode dar início da elaboração da angústia. Essa probabilidade pode ser encontrada no núcleo do trabalho de autores que, na contemporaneidade, confiram o valor terapêutico do conto. ${ }^{(15)}$

Diante disso, é interessante ressaltar que essa relação de proximidade entre o conto e o sonho, presente nos escritos de Freud, também é constatada na obra de outros autores contemporâneos como: Bettelheim, (9) Lafforgue,(11) entre outros. ${ }^{(4)}$ Interessa, também, assinalar que Freud se utilizou dos "contos de fadas" para interpretar os sonhos e melhor entender os conflitos neuróticos de seus 
pacientes, utilizando ambos, contos e sonhos, com vistas a trazer representações (latentes) significativas sobre esses conflitos.

Kaës ${ }^{(16)}$ conclui a partir do artigo de Freud (1913), que os contos dispõem de um material para satisfação de um desejo infantil, tanto quanto nos sonhos. Gutfreind ${ }^{(4)}$ observa que o conto e o sonho seguem os mesmos recursos como estrutura, ou seja: dramatização, deslocamento, condensação e simbolização. Portanto, cabe dizer que Freud, de certa forma, incumbiu a seus seguidores, tanto quanto a estudiosos contemporâneos, a responsabilidade de estudar, através do viés psicanalítico, os mitos, os contos e as origens de nossa civilização. Isso fez com que o pensamento de Kaës, acima mencionado, se dirigisse aos trabalhos de Ferenczi $(1913,1914,1918$, 1923a e 1923b) e Melanie Klein (1930).

Interessa assinalar que a psicanálise apresentou nomes influentes para dar início às pesquisas referentes à função terapêutica do conto, estudando conceitos específicos como: "triunfo do ego", "organização do pensamento" e "abertura de espaço potencial". Nesse sentido, é importante lembrar o renomado Bruno Bettelheim que foi quem exerceu a posição de precursor nesse domínio, sendo o primeiro a analisar e registrar - do ponto de vista psicanalítico -, as ideias sobre a importância das histórias de fadas na vida das crianças, com sua obra clássica: A Psicanálise dos Contos de Fadas (1976).(4,5)

Foi percebido através dos estudos que, os autores pesquisados trilharam (ainda que de forma implícita), o mesmo percurso compreensivo sobre o problema central que suscitou essa pesquisa, na medida em que indicam uma positividade do uso do conto de fadas para a saúde psíquica das pessoas.

Apesar de haver vários conceitos que confirmam os efeitos que o conto pode exercer sobre os sujeitos, e que sem dúvida os estudos comprobatórios sobre essa eficácia sejam abundantes, contudo alguns autores, como Gutfreind, (4) consideram que em relação a sua utilização terapêutica, ainda se tratar de um campo pouco explorado.
Para Gutfreind, (4) o mais importante para a teoria psicanalítica em relação ao conto, é o fato desta poder continuar avançando em seus estudos e registros relacionados ao mesmo. Nesse sentido, o autor enfatiza que, "[...] não foram necessários mais do que um adulto com vontade de contar e um patinho feio com vontade de se encontrar, para aliviar o sofrimento de uma criança triste, mas, como todas, querendo ser feliz como Béatrice". (p. 154).

\section{A CRIANÇA HOSPITALIZADA}

A condição de hospitalização pode ser considerada como um momento muito impactante para uma criança, pois interfere na sua qualidade de vida tanto física quanto psicológica. Uma vez internada, ela é transportada para um ambiente geralmente desconhecido, associado ao sofrimento, à dor, e algumas vezes à morte.

Autores de diferentes áreas de conhecimento, principalmente da área da saúde, baseados em pressupostos teóricos, pesquisas e práticas profissionais, têm discutido os efeitos dos processos da hospitalização infantil, dado que essa experiência é potencialmente traumática e dolorosa. ${ }^{(7,17-19)}$ Nesse sentido, Chiattone, ${ }^{(8)}$ Kudo e Bagio Maria, ${ }^{(19)} \mathrm{Ne}$ der, ${ }^{(20)}$ Angerami, ${ }^{(21)}$ e Campos, ${ }^{(22)}$ da literatura demarcada, sugerem que a equipe de saúde tenha sempre como objetivo principal do atendimento a redução do sofrimento da criança hospitalizada, proporcionando-lhe saúde e bem estar, e, sobretudo, tornando-a um sujeito ativo dentro do processo de internação e doença.

De acordo com Chiattone, ${ }^{(8)}$ a equipe de saúde deve ter o conhecimento necessário para entender que a doença atinge a criança como um todo. A autora afirma que durante o período do adoecimento a criança encontrar-se-á prejudicada do ponto de vista físico e psicológico, comprometendo assim seu equilíbrio emocional.

Além desses fatores citados anteriormente, a criança hospitalizada enfrenta uma situação nova, onde tudo é desconhecido. Diante disso, ela pode 
criar certa resistência para entender, concordar e suportar as limitações nas atividades diárias causadas pela estrutura física do hospital, as rotinas impostas, bem como as explorações médicas, muitas vezes invasivas, dolorosas e traumatizantes, apesar de serem imprescindíveis à realização do processo de diagnóstico e tratamento, haja vista que no contexto hospitalar a realidade é imposta. ${ }^{(7,8,19)}$

O impacto sobre a criança, e o sentimento de incerteza ou ansiedade em relação à realidade hospitalar, poderá fazer aparecer as diversas fantasias, inclusive as persecutórias, ${ }^{3}$ a respeito da doença, e do que pode acontecer. É nesse sentimento de ameaça que surgirá um dos maiores problemas de adaptação da criança no hospital, a saber: o medo do desconhecido - geralmente presente durante o período de internação. ${ }^{(7,8)}$

As fantasias criadas pelas crianças diante da internação geralmente são assustadoras, tendo em vista desencadearem sentimentos de "perda", "abandono" e "solidão" - palavras que para $\mathrm{Ni}$ gro(7) podem definir o termo "impacto", ao referir-se à situação de internação infantil. A autora ressalta que o sentimento de solidão provocado pela hospitalização faz parte dessa realidade. Nessa ocasião a criança é afastada de modo inesperado de sua casa, de sua família, da escola, de seus brinquedos (objetos de amor) e dos seus amigos, ocorrendo assim a perda do seu referencial, ao mesmo tempo em que se depara com um ambiente cheio de tensão e ameaçador: o hospital. $(7,23)$

Autores, inclusive, Bettelheim, ${ }^{(9)}$ consideram que em se tratando do abandono, não existe algo mais ameaçador do que nos sentirmos nessa condição ou de sermos deixados inteiramente sós. De acordo com esse autor, a Psicanálise chamou isso de: "[...] o maior medo do homem - angústia de separação; [...]" (p. 205).

Nigro(7) em sua prática hospitalar, junto a crianças hospitalizadas, no que diz respeito às emoções e "fantasias persecutórias e assustadoras", provocadas pela internação, compreende essa experiên-

\footnotetext{
3 A criança imagina a doença e a internação como um castigo, relacionados a acontecimentos externos pela falta de obediência aos pais ou por não ter respeitado os regulamentos escolares. ${ }^{(7,8)}$
}

cia como um evento relevante na vida de qualquer sujeito, além de torná-la um episódio "estranho" e "impactante". Com isso, a autora cita Freud (1919), em Das Unheimiliche, ${ }^{4}$ para dizer "[...] que a sensação de estranheza provoca ansiedade e inquietação, deixando o sujeito indefeso [...]" (p. 18), - sensações bastantes experienciadas no contexto hospitalar.

Durante o processo de hospitalização também é registrada uma quebra parcial ou total dos cuidados maternos. Segundo Chiattone, ${ }^{(8)}$ esse acontecimento

[...] traz à criança muita angústia, uma exagerada necessidade de amor, sentimentos de vingança e, consequentemente, culpa e depressão. A forma pela qual a criança reage a estas perturbações pode resultar em distúrbios emocionais graves e numa personalidade instável. (p. 29).

A autora citada afirma que: "Todas as crianças estão sujeitas aos efeitos físicos, intelectuais, emocionais e sociais da privação materna [...]". Sendo assim, ela acrescenta que a criança pode "[...] reagir apaticamente, ou, ao contrário, agressivamente, dificultando a atuação da equipe de saúde ao rejeitar a medicação, as restrições, os exames, e as dietas", interferindo no resultado terapêutico ( $p$. 29-30).

A reação de apatia é uma das mais preocupantes quando acontece dentro do contexto hospitalar. Raramente a criança que apresenta falta de afeto reagirá à internação. Dessa forma,

a equipe de saúde precisa estar atenta para a criança que aparenta ser bem comportada, não dar trabalho, tampouco preocupação. Diferentemente em manifestações de choro, de desespero, do medo e da ansiedade, consideradas expressões salutares, surgirá um desequilíbrio interno se comparados com os comportamentos apáticos. Em decorrência desse sintoma poderão aparecer consequências graves, ou seja, sequelas que muitas vezes são consideradas irreversíveis, causadas pelo período de internação, como, por exemplo, um comprometimento no desenvolvimento de sua personalidade. ${ }^{(8)}$

4 O estranho. ${ }^{(24)}$ 
Spitz ${ }^{(25)}$ no livro O primeiro ano de vida, afirma que a falta de afetividade provocada pela ausência dos cuidados maternos "[...] poderá gerar quadros patológicos graves, como a síndrome do hospitalismo [...]" (p. 7 ).

Nigro(7) argumenta que as observações de Spitz ${ }^{(2)}$ confirmam os efeitos nocivos causado pela doença, separação obrigatória e forçada entre mãe-filho durante a internação hospitalar, sobre o psiquismo infantil. Cito:

a carência emocional gerada pela privação do afeto pode levar a duas situações graves descritas por ele. São elas: a depressão anaclítica como consequência da privação emocional parcial e o marasmo, consequência emocional total, que pode provocar até a morte, caso não apareça um substituto materno significativo $[\ldots] \cdot{ }^{(25)}$

As regressões que se instalam devido à privação materna ou de um substituto que possa restabelecer os cuidados afetivos, mesmo que haja ótimas condições materiais de higiene e cuidados, podem ser observadas na criança em situação de hospitalização, ou seja, um retardo no desenvolvimento geral tendo em vista que é a mãe quem lhe transmitirá os dados necessários para que esse desenvolvimento aconteça. ${ }^{(26)}$

Reiterando o impacto psicológico da hospitalização sobre o psiquismo infantil, Nigro(7) e Goldenberg(27) apontam para uma reflexão sobre as mudanças de ordem psicológica que geram desarmonia psíquica.

De acordo com Simonetti, ${ }^{(28)}$ as mudanças de ordem psicológica correspondem a algumas posições que o paciente ocupa no seu processo de adoecimento. Sendo assim, os profissionais da equipe de saúde não têm como influenciar sobre o que deva ocorrer a esse respeito sem que o paciente esteja pronto. Para o autor, essa é uma estratégia que se aproxima da realidade, e que isenta o psicólogo de assumir a responsabilidade de intervir para que a reação do paciente aconteça.

Portanto, é importante lembrar que:

O psicólogo não é, a priori, um modificador de comportamentos desadaptativos, como poderia supor a medicina, ele é um facilitador do trabalho de elabo- ração psíquica, trabalho este que pode levar a uma mudança ou não. Na psicologia hospitalar a mudança vem como resultado, não como objetivo. $\mathrm{O}$ compromisso do psicólogo hospitalar é com a verdade do sujeito, e não com a mudança de comportamento. ${ }^{(28)}$ (p. 118).

Partindo-se do pressuposto de que o paciente passa por algumas posições em seu processo de adoecimento, isto é, a forma como reage à doença, o autor citado discorre sobre alguns dos processos psíquicos que interferem na vida do sujeito durante o período de hospitalização. Para tanto, ele apresenta as quatro posições principais: negação, revolta, depressão e enfrentamento, organizadas em uma ilustração gráfica intitulada "Órbita em torno da doença". ${ }^{5}$ Sem obedecer a uma ordem específica, o paciente pode assumir e mudar de posição a qualquer momento, diz o autor.

É importante destacar que essas posições não são próprias para a doença, elas constituem-se nas várias formas "[...] que os humanos dispõe [sic] para enfrentar crises, receber notícias ruins, lidar com mudanças, encarar a morte [...]. ${ }^{(28)}$ (p. 38).

De acordo com a literatura consultada, a negação geralmente é a primeira posição apresentada pelo sujeito, e é considerada como uma posição de defesa psicológica; é um estado em que o paciente nega a existência da doença, podendo assim aceitar ou se recusar ao tratamento. Portanto, não se caracteriza como uma das etapas apresentadas pela criança hospitalizada, uma vez que ela não tem ainda esse amadurecimento psíquico para se expressar, como fazem alguns pacientes adultos. Nesse sentido, a revolta, a depressão e o enfrentamento são consideradas as mais relevantes nessa realidade infantil.

Das mudanças psicológicas manifestadas pela criança internada, a revolta é a que geralmente aparece primeiro. Nessa condição ela se encontra propensa a manifestações agressivas, e até mesmo a se comportar de maneira violenta como forma de defender sua integridade física e psíquica. O hos-

5 Termo "Órbita" segundo Simonetti, ${ }^{(28)}$ refere-se a "movimento em torno de". (p. 38) 
pital é visto pela criança como um ambiente hostil, causador do seu sofrimento e das privações de sua liberdade e autonomia. ${ }^{(7,8)}$ Esse é um momento que o psicólogo hospitalar deve se encontrar preparado para lidar com pacientes nessa fase de revolta, lhe proporcionado uma escuta diferenciada, procurando entender os seus conflitos.

A segunda posição na órbita da doença é caracterizada pela depressão. O referido autor considera essa etapa diante da doença como uma reação esperada, dessa forma ele sugere que o psicólogo deva tratar seu paciente sem fazer critica a essa etapa, tornando-se um suporte até que ele possa sair dessa fase difícil e passe para outra posição, ou seja, a mais esperada: o enfrentamento. Entretanto, acrescenta que nos casos em que os sintomas depressivos se tornam acentuados ou prolongados, passando de fase e se transformando em um estado, há que se considerar a possibilidade de um tratamento médico com uso de medicação.

A depressão também é caracterizada como uma fase de elaboração psíquica. ${ }^{6} \mathrm{O}$ sujeito adoecido fecha-se em si mesmo, ao responder a uma economia psíquica, podendo aos poucos, no ritmo do seu tempo, transformar essa energia e mudar de posição frente à sua doença. ${ }^{(29)}$

Com esse respeito Simonetti ${ }^{(28)}$ diz que:

Freud demonstrou em "Luto e Melancolia" (1980, vol. XIV) que na depressão a energia psíquica abandona os objetos externos e se volta para o interior, na tentativa de realizar um trabalho psíquico, a saber, o trabalho de elaboração das perdas, reais e imaginárias. ${ }^{(30)}$ (p. 121-122).

O enfrentamento é a terceira etapa que se apresenta nesse movimento em torno da doença. É um dos momentos mais importantes para o sujeito, e o mais esperado pela equipe de saúde, principalmente pelo psicólogo, que não deve se sentir angustiado caso o paciente demore a se colocar nessa posição. ${ }^{(28)}$

Segundo o mesmo autor, apesar do paciente se encontrar na posição de enfrentamento, e do

\footnotetext{
A) Expressão utilizada por Freud para designar em diversos contextos, o trabalho realizado pelo aparelho psíquico [...]. (p. 143). ${ }^{(29)}$
}

que possa aparentar, ele ainda necessita de muito apoio. Nesse momento, o paciente passa por uma fase significativa de elaboração psíquica. Assim, a presença do profissional de psicologia torna-se de suma importância nesse processo, pois é ele que possibilita e tem como principal ferramenta a escuta diferenciada, que abre as possibilidades para que a subjetividade possa fluir, é "que aguenta escutar coisas alegres e coisas tristes, [...]" (p. 123). E enfatiza: "[...] este trabalho que o psicólogo realiza diante da doença lhe é específico, ou seja, além dele nenhum outro profissional da área da saúde foi treinado para isso". (p. 14).

A posição de enfrentamento também se caracteriza

$$
\begin{aligned}
& \text { pela alternância entre as posturas de luta e de luto } \\
& \text { em relação à doença. Então as intervenções do psi- } \\
& \text { cólogo hospitalar deve se dar no sentido de facilitar } \\
& \text { esse movimento entre a luta e o luto. O enfrenta- } \\
& \text { mento é luta e luto juntos, e não um ou outro. Se } \\
& \text { o paciente é "muito luta", ajude-o a fazer o luto, e } \\
& \text { se ao contrário, ele é "muito luto", ajude-o a lutar. } \\
& \text { (p. 124). }{ }^{(28)}
\end{aligned}
$$

Partindo-se dos pressupostos acima considerados, pode-se dizer que um dos recursos que o psicólogo hospitalar pode utilizar no trabalho com crianças internadas, é a narração do conto de fadas, por este fazer parte da vida cotidiana, ser importante para o desenvolvimento psíquico, auxiliar no entendimento da atividade mental, além de ajudar na promoção de elaboração psíquica. Todavia para que haja um melhor entendimento sobre esta ferramenta, a melhor forma é conhecer como a mesma pode ser usada nesse contexto de atuação: o hospital.

\section{O PSICÓLOGO HOSPITALAR E O USO DO CONTO}

"Era uma vez", "Há muito tempo atrás", "Em um lugar bem distante" - é assim que geralmente os contos de fadas iniciam, onde há falta de uma verdadeira noção de localização e temporalidade. Segundo Velay-Vallantin, (2) o que se pode constatar 
sobre os estudos literários do conto é de que: "o conto é fora do tempo" (p. 27).

Os contos de fadas tiveram como principais precursores o francês Charles Perrault (1628-1703), os irmãos Jacob Grimm (1785-1863) e Wilhelm Grimm (1786-1859), e o poeta e romancista dinamarquês Hans Christian Andersen (1805-1875), considerado por muitos autores como o primeiro escritor a dedicar-se à narrativa infantil. $(5,6,12)$

Difundidas no mundo inteiro, as histórias de fadas se transformaram em verdadeiros artifícios para o universo infantil, despertando ao mesmo tempo medo e deslumbramento, como afirma Tatar. ${ }^{(6)} \mathrm{Em}$ seus enredos os personagens têm características próprias, onde o herói ou a heroína enfrentam uma série de desafios para que no final possam triunfar.(31) Para Bettelheim, ${ }^{(9)}$ o que caracteriza esses contos é a presença de um dilema existencial.

Os contos de fadas são cheios de magia e deslumbramento. Entre seus diversos personagens estão as fadas, bruxas, príncipes e princesas, reis e rainhas, lobos, ogros, gigantes e monstros aterrorizantes, e também são representados por objetos que ganham vida e animais falantes. Além de personificarem o bem ou o mal, eles passam por transformações e metamorfoses em contextos de muito mistério e encantamento. ${ }^{(12,31)}$

Apesar de se estar vivendo, hoje, a era da tecnologia moderna, Kehl, (1) Corso e Corso, ${ }^{(5)}$ Radino, ${ }^{(12)}$ entre outros, afirmam que os contos de fadas continuam encantando as crianças das gerações dos computadores, videogames, jogos de RPG, TV, etc. Kehl(1) ressalta que "a capacidade de sobrevivência dos melhores contos [...] consiste em seu poder de simbolizar e "resolver" os conflitos psíquicos inconscientes que ainda dizem respeito às crianças de hoje". (p. 16). Cito:

Como a criança ainda não delimitou as fronteiras entre o existente e o imaginoso, entre o verdadeiro e o verossímil [...], todas as possibilidades da linguagem the interessam para compor o repertório imaginário de que ela necessita para abordar os enigmas do mundo e do desejo.
A autora pontua que, ainda que as crianças tenham acesso a todas as tecnologias do mundo moderno,

[...] isto não significa que a zona estranhamente familiar das manifestações do inconsciente tenha se reduzido [...] à ousadia das imagens publicitárias. Nossas crianças continuam interessadas em seu próprio universo de mistérios, que sobrevive à aparente transparência da era das comunicações, com seu imperativo de tudo mostrar, tudo dizer, tudo exibir. (p. 17).

E ratifica Bettelheim ${ }^{(9)}$ quando diz que:

É bem verdade que, num nível manifesto, os contos de fadas pouco ensinam sobre as condições específicas da vida na moderna sociedade de massa; eles foram inventados muito antes do seu surgimento. No entanto, por meio deles pode-se aprender mais sobre os problemas íntimos dos seres humanos e sobre as soluções [...] para as suas dificuldades em qualquer sociedade do que com qualquer outro tipo de história compreensível por uma criança. (p. 11-12).

Sendo assim, as histórias de fadas são descritas - com base em estudos psicanalíticos - como uma forma de literatura onde se encontra um significado mais profundo da existência humana. Entre vários aspectos, esses contos se distinguem por ajudar o sujeito a pensar sobre si mesmo, sobre o mundo, bem como transmitirem mensagens importantes à mente infantil, tanto quanto a de adultos, em qualquer nível que ela se encontre no momento: consciente, pré-consciente e inconsciente. $(4,5,6,6,9,12)$

Bettelheim ${ }^{(9)}$ pontua que a mensagem dos contos de fadas é a de transmitir à criança que um enfrentamento das fases difíceis da vida se torna inevitável. Diante disso, o autor afirma que esse desafio "[...] é parte intrínseca da existência humana - mas que, se a pessoa não se intimida [...]" e consegue se defrontar "[...] resolutamente com as provocações inesperadas e muitas vezes injustas, dominará todos os obstáculos e ao fim emergirá vitoriosa". (p. 15).

Os contos de fadas despertaram a atenção de psicólogos e psicanalistas, entre os quais se distingue o próprio Bettelheim. ${ }^{(4,5,5,6,12)} A$ partir das últimas décadas, profissionais, como, por exemplo, Celso Gutfreind; Diana e Mário Corso; Gilberto Sa- 
fra, entre outros, têm se utilizado dos contos de fadas como instrumento terapêutico no auxílio de crianças, tanto quanto de adolescentes para resolver seus conflitos, com base nos conteúdos trazidos pelos mesmos.

Radino ${ }^{(2)}$ ressalta que a fantasia é o que nos move. A autora nos lembra de que desde o nascimento, para nossa sobrevivência psíquica, criamos fantasias tão importantes para o controle de nossas angústias, tanto quanto para a realização de nossos desejos. E afirma que, para se compreender como os contos de fadas podem auxiliar a criança, como representantes de acontecimentos psíquicos, diferente da realidade factual, é preciso entender o significado de realidade psíquica. ${ }^{7}$

Ao adentrarem no mundo da fantasia e da imaginação, as crianças encontram um lugar seguro onde seus medos podem ser confrontados, vencidos e afastados. Dessa forma, é possível dizer nas palavras de Tatar, ${ }^{(6)}$ que "a verdadeira magia do conto de fadas reside em sua capacidade de extrair prazer da dor", e que além de darem "[...] vida às figuras sombrias de nossa imaginação como bichos-papões, bruxas, canibais, ogros, e gigantes, os contos de fadas podem fazer aflorar o medo, mas no fim sempre proporcionam o prazer de vê-lo vencido" (p. 10). Nesse sentido, Radino ${ }^{(12)}$ afirma que apesar desses personagens serem aterrorizantes, consegue acalmar a criança por tornar visíveis problemas que todo sujeito precisa elaborar, como a morte, o desamparo, a separação, entre outros.

Para Bettelheim:(9)

Os contos de fadas são ímpares, não só como uma forma literária, mas como obras de arte integralmente compreensíveis pela criança como nenhuma obra de arte o é. Como sucede com toda grande obra de arte, o significado mais profundo do conto de fadas será diferente para cada pessoa, e diferente para a mesma pessoa em vários momentos da vida. A criança extrairá significados diferentes do

\footnotetext{
7 Expressão utilizada muitas vezes por Freud para designar aquilo que no psiquismo do sujeito apresenta uma coerência e uma resistência comparáveis às da realidade material; trata-se fundamentalmente do desejo inconsciente e das fantasias conexas. Quando Freud fala de realidade psíquica, não faz simplesmente para designar o campo da psicologia concebida como possuidora da sua ordem de realidade própria e suscetível de uma investigação científica, mas aquilo que para o sujeito assume valor de realidade no seu psiquismo. ${ }^{(29)}$ (p. 426)
}

mesmo conto de fadas, dependendo de seus interesses e necessidades do momento. Tendo oportunidade, voltará ao mesmo conto quando estiver pronta a ampliar os velhos significados ou substituí-los por novos. (p. 20-21).

O "conte outra vez" é uma das maneiras que a criança encontra para tomar posse de suas emoções e assim poder organizá-las, ao mesmo tempo em que ela se utiliza da simbologia dos contos para brincar com sua realidade interna, o que a possibilitará exteriorizar seus conflitos. ${ }^{(12)}$ Corso e Corso(32) observam que: "A criança não só entra na fantasia proposta, como se apropria da fantasia para seu uso particular: recorta, monta, cola, inventa partes, tudo para fazer histórias na medida de sua necessidade" (p. 46). Tatar ${ }^{(6)}$ pontua que os contos disponibilizam a base para serem recontados, mas, que na maioria das vezes poderão exigir a intervenção dos adultos. Sendo assim, no contexto hospitalar, cabe ao psicólogo essa tarefa, como profissional que pode se utilizar dos mesmos para tal.

Segundo Bettelheim, (9) a criança sabe entre os vários contos qual o mais adequado à sua situação no momento, e que sozinha não seria capaz de enfrentar; ela também sabe qual a parte da história Ihe dará suporte para enfrentar uma situação difícil. O autor afirma que o conteúdo inconsciente é o mais secreto e o mais conhecido. Acrescenta que, sem que se perceba, o inconsciente como no conto de fadas leva o sujeito a lugares estranhos, longínquos e, ao mesmo tempo, os mais conhecidos.

Tatar(6) afirma que:

[...] as histórias são irresistíveis, pois oferecem oportunidade de falar, debater, deliberar, tagarelar e conversar [...]. E a partir do emaranhado dessa conversa e tagarelice, começamos a definir nossos próprios valores, desejos, apetites e aspirações [...]. (p. 15).

Conforme Pazinato, (31) os contos de fadas são usados no contexto hospitalar, objetivando a elaboração de conteúdos psíquicos. Nesse sentido, a autora acrescenta que a relação "contista-obra-ouvinte" poderia ser considerada como um exercitar da criatividade, vista por Winnicott ${ }^{(33)}$ como seme- 
Ihante ao brincar (p. 296). Em Winnicott, (34) o brincar é um facilitador do crescimento, conduzindo assim à saúde.

Com referência ao brincar, Crepaldi(35) faz a seguinte elucidação:

Verificamos que, em se tratando de crianças, o que caracteriza o estado de doença é a incapacitação para o brinquedo, o estado de prostração que se opõe à vivacidade e atividade da criança, o prejuízo em seu desenvolvimento, somados ao aparecimento do sintoma ou conjunto de sintomas. (p. 75)

Nigro(7) compartilha do mesmo ponto de vista do autor acima citado, quando diz que

[...] uma das manifestações características do "estar doente", é justamente a dificuldade de manter a atividade lúdica". A autora afirma que: "Sem o brincar a criança perde as vias de expressão de suas emoções, perde o espaço no qual poderia estar repetindo situações traumáticas [...]. (p. 75).

Corso e Corso ${ }^{(32)}$ pontuam, nas palavras de Freud, que "a obra literária, assim como o devaneio, é uma continuação ou substituto do que foi o brincar infantil". Para esses autores, o recurso lúdico serviria como um treino, para o que se segue, ou seja, uma tentativa de perceber o mundo através da vivência. Para eles, com as narrativas infantis acontece o mesmo: "[...] história são brinquedos verbais, são peças de um sistema lógico que a criança pode encaixar à sua maneira tanto para antecipar papéis que ela julga que irá passar quanto para elaborar o que já passou". (p. 46).

Safra, (36) em seu livro Curando com histórias, menciona que a utilização de histórias infantis, como ferramenta de intervenção, por ser comparável à forma de pensar da criança e também por promover o surgimento do "espaço potencial" e dos "fenômenos transicionais", ${ }^{9}$ provavelmente possibilitará a recuperação do "devir de seu self". Segundo o autor, o espaço potencial dá oportunidade

\footnotetext{
8 Esta seria a terceira área da vida de um ser humano - entre a realidade subjetiva e a realidade compartilhada - que não pode ser ignorada pois constitui uma área intermediária de experimentação para a qual contribuem tanto a realidade interna quanto a externa. (p. 29) $)^{(38)}$

9 Esses fenômenos acontecem entre a vivência da ilusão e a utilização dos objetos culturais. Para Safra,(36) as histórias é um bom exemplo para os fenômenos transicionais, pois, no universo "do faz de conta", a criança tenta se desfazer de suas "tensões" provenientes do encontro com a realidade interna e a externa.
}

ao indivíduo de conviver com a realidade objetiva de maneira criativa, possibilitando assim uma amplitude para contatar com o mundo externo de forma sadia, onde se tem uma abertura para o espaço das brincadeiras.

De acordo com Bettelheim, ${ }^{(9)}$ o mais importante dos contos de fadas para o indivíduo em fase de desenvolvimento vai além de simples ensinamento das formas corretas de como comportar-se no mundo "[...] - tal sabedoria é plenamente suprida na religião, nos mitos e nas fábulas". O autor acrescenta que: "As histórias de fadas não pretendem descreve o mundo tal como ele é, e nem dão conselhos sobre o que alguém deva fazer". Portanto, no que se refere a este assunto, ele afirma que: "O conto de fadas é terapêutico porque o indivíduo encontra suas próprias soluções, por meio da contemplação daquilo que a história parece sugerir acerca de si e de seus conflitos íntimos nesse momento da vida".(9) (p. 36).

Sunderland ${ }^{(37)}$ considera uma história como um instrumento terapêutico eficaz a partir do momento em que a criança utiliza formas criativas de ser e de lutar, nela contidas. Todavia, aquele pode não ser o momento propício para ela. Conforme a autora, um conto utilizado de forma terapêutica é como um "ingresso" para acessar inconsciente infantil, frequentemente aceito, quando a história é bem escolhida, a partir das questões do sujeito. Dessa forma, a criança ouve a história com atenção, porque o narrador consegue entrar em seu mundo com

"cuidado" e "compreensão". Nesse caso, a autora sugere que a história deve ser contada quando a criança estiver "aberta" e "receptiva".

Segundo a mesma autora, para que uma história tenha um impacto psicológico sobre a criança, devem estar contidas questões pelas quais ela está passando, bem como recursos a serem utilizados para enfrentá-los, que é um verdadeiro desafio. Portanto, faz-se necessário conhecer sua história, sua queixa, suas dificuldades, bem como o contexto no qual está inserida. Interessa lembrar que, Bettelheim (9) pontua que o conto "[...] não poderia ter seu impacto psicológico sobre a criança se não 
fosse primeiro e antes de tudo uma obra de arte". (p. 20).

Bettelheim(9) chama a atenção para o fato de que a criança nem sempre tem consciência de seus problemas, podendo expressá-los no conto de fadas, e de forma simbólica, e ainda em comportamentos no lugar de suas lutas internas e externas. Os dilemas apresentados pelos personagens dão coragem à criança para enfrentar a "realidade existencial" pela qual ela está vivenciando. No conto, os personagens "[...] são identidades e pautas sociais, alternativas, que em sua flexibilidade, promovem [...]" à criança hospitalizada "[...] o sair-para-além-do-leito, e habitar mundos, que divisam o eu para a cultura e a história [...]".(31) (p. 305).

Para se narrar uma história, para uma criança, Sunderland(37) reforça a importância de se ter conhecimento sobre os temas que mais aparecem em suas brincadeiras, em seus sonhos, nos sintomas neuróticos e em sentimentos expressados por meio de suas ações. Para tanto, a autora disponibiliza uma lista de temas dos quais alguns são mais frequentemente apresentados pela criança hospitalizada, como:

Sentir-se indesejada; Sentir-se indefesa ou insignificante; Querer desesperadamente que alguém a ame; Sentir-se sozinha; Sentir-se perdida; Sentir medo de tudo o que é novo ou diferente; Viver com medo de fazer alguma coisa errada; Sentir vontade de erguer muros para manter os outros afastados; Sentir-se invadida ou controlada; Sentir vontade de bater, ferir ou destruir; Sentir-se confusa por dentro; Sentir-se má e Sentir que nada tem sentido. (p. 39-40).

Ao escrever sobre como um conto "eficaz" funciona para a criança, a autora acima citada, mostra quatro maneiras que podem repercutir sobre sua vida, e sobre seus sentimentos mais difíceis, são elas:

1) Apresenta opções sobre o que fazer diante de um grande obstáculo; 2) Apresenta novas possibilidades e soluções criativas para superar problemas aparentemente insuportáveis; 3) Mostra como lidar de modo eficaz e menos doloroso com problemas emocionais comuns; e 4) Mostra que novas maneiras de ser é possível [sic]. (p. 28).
Assim, a história disponibiliza o tempo necessário para que a criança possa pensar sobre sua situação, suas emoções, e sua maneira de ser. Safra ${ }^{\left({ }^{6}\right)}$ diz que é nesse ponto que se encontra o grande valor das histórias, pois, através delas, o narrador tem a oportunidade de apresentar à criança algumas representações sobre seus conflitos, além de poder respeitar seu tempo de "hesitação". Então, a criança pode reconhecer, com segurança, alguns dos personagens apresentados na história, e que pertencem à sua realidade psíquica, sem que se sinta invadida por conteúdos bruscos interpretativos, diante da qual precisa reagir.

De acordo com Pazinato, ${ }^{(31)}$

O psicólogo [...] alicerça sua atividade na percepção situacional, aberta e dinâmica de seu contexto social composto pelas relações saúde-doença, cultura hospitalar-comunidade, corpo-vivido-significados da existência (p. 297).

É nesse contexto que o psicólogo hospitalar vê o paciente de acordo com as suas necessidades, capacidades, apelos e desejos, e através de manifestações que se aproximam de sua realidade. Sabendo que, a opção de contar histórias como recurso terapêutico, em um hospital, pode ser entendida como uma forma de se deparar com muitos desafios, envolvidos com a comunicação e com a aprendizagem proposta a partir da execução desse papel. Também requer condições ambientais para que ela aconteça, como certa dimensão silenciosa, atenta, curiosa, e interessada em fazer descobertas.

As vivências do psicólogo hospitalar em relação aos pacientes geralmente são acompanhadas de manifestações de ansiedade, medo, estranhamento, angústia, tristeza, perda e dor. Dessa maneira, esse profissional precisa estar preparado para disponibilizar acolhimento, atenção e cuidados frequentes, tendo em vista que em muitos "contos de fadas" estarão contidos enredos que se aproximam da vida real. Portanto, ele necessita estar consciente do que pode acontecer no setting hospitalar, ou seja, pronto para desempenhar o papel do profissional dentro do hospital. 
Radino ${ }^{(12)}$ observa que o conto de fadas não é o único recurso de intervenção com crianças para ajudá-las no enfrentamento de obstáculos, a lidar com as angústias e auxiliá-las no desenvolvimento de suas personalidades, mas pode ser uma importante ferramenta de trabalho. Nesse sentido, autores como Corso e Corso ${ }^{(5)}$ também corroboram dessa observação. Todavia, apesar de considerar o conto como objetivo terapêutico um instrumento muito importante, Safra ${ }^{(36)}$ discorda da sua utilização de forma "indiscriminada", ou seja, como já mencionado, é preciso conhecer a realidade do sujeito. O autor pontua que, do contrário, "corre-se o risco de contar à criança uma história que intensifique suas ansiedades, ao invés de ajudá-la na elaboração das mesmas" (p. 26).

Como um dos exemplos de conto de fadas que pode servir de modelo para ser utilizado como instrumento terapêutico, com crianças, no contexto hospitalar, é possível citar, o já mencionado, "O Patinho Feio" de Hans Christian Andersen (18051875), por ser amplamente conhecido e que, segundo Corso e Corso(5) o mesmo traduz as angústias vividas pelo mundo infantil.

De acordo com Tatar, ${ }^{(6)}$ o referido conto reflete o sofrimento, a dor física e a angústia do herói. Nesse sentido, a história do "Patinho Feio" se aproxima de algumas das experiências vividas pela criança durante o processo de internação hospitalar. Sendo assim, ela, provavelmente, será capaz, portanto, de identificar-se com esse personagem para resolver seus conflitos.

Diante de tudo que foi exposto, conclui-se que a utilização dos contos de fadas como um dos recursos terapêuticos com crianças, pelo psicólogo hospitalar, se torna relevante tendo em vista esse profissional estar ajudando a minimizar as dificuldades enfrentadas por estas durante o período de hospitalização, bem como auxiliando esses pequenos sujeitos em seus processos de elaboração psíquica.

\section{CONSIDERAÇÕES FINAIS}

Considerando os estudos feitos sobre a temática "os contos de fadas como recurso terapêutico", é de crer que os mesmos são atemporais. É possível dizer que eles desafiaram o tempo e que conseguiram chegar até os dias atuais, apesar de todo avanço tecnológico do mundo moderno. É possível dizer, também, que as histórias de fadas continuam encantando as crianças das gerações dos computadores, da TV, dos jogos eletrônicos, entre outros.

A princípio, buscou-se através dessa pesquisa, com base na questão central, saber qual a importância da utilização do conto de fadas como recurso terapêutico com crianças hospitalizadas, a partir do debate colocado por autores psicanalistas como Bruno Bettelheim, Celso Gutfreind, Diana e Mário Corso, Glória Radino, Gilberto Safra, entre outros. Nesse sentido, foi possível constatar a existência de vários conceitos e formas que esta "arte literária" - o conto de fadas - dispõe como função terapêutica, com base nos estudos psicanalíticos. Dessa forma, a Psicanálise veio contribuir para um melhor entendimento sobre a concepção da infância, transformando o conto em uma das ferramentas importantes para auxiliar as crianças na elaboração de conflitos internos. Compreende-se, portanto, que o contato entre a criança e os contos de fadas contribui efetivamente com o seu equilíbrio psíquico.

A hospitalização infantil, geralmente, traz as marcas do sofrimento, da angústia e do medo, causada pela doença e pela ruptura do convívio social e familiar. No ambiente hospitalar, a criança encontra-se cercada por um ambiente desconhecido e ameaçador, que consequentemente interfere no processo de elaboração psíquica e cura.

Considerando-se o conto de fadas como instigador mental e relevante para o desenvolvimento psicológico da criança, observa-se sua importância como um dos recursos terapêuticos a ser utilizado pelo 'Psicólogo' no contexto hospitalar, 
ainda que desafiando as limitações do tempo e lugar. Portanto, cabe salientar que o psicólogo tem um papel fundamental nesse processo, ou seja: psicólogo-conto-criança.

O objetivo desse trabalho não foi o de esgotar as pesquisa em torno do tema, mas através dele incentivar novos estudos, como por exemplo, a relação entre o conto e o sonho, tendo em vista ambos serem considerados como vias de acesso para o inconsciente. Mas, principalmente, o de reforçar o interesse do "Psicólogo Hospitalar" em utilizar-se do "conto de fadas" como uma das ferramentas importantes na diminuição do impacto causado sobre a criança no processo de internação hospitalar, pois, quanto à sua utilização terapêutica, apesar de sua eficácia, ainda é considerado um campo pouco explorado.

Diante das limitações propostas por esta pesquisa, tendo em vista se tratar de um estudo realizado e voltado fundamentalmente para conceitos, ressaltando a função terapêutica do conto de fadas, a mesma se encontra aberta a outras possibilidades de aprofundamento, como por exemplo, o estudo através de pesquisa de campo, que possibilitará trazer maiores discussões e resultados em relação ao tema. Todavia, esta poderá servir, além de tantas outras, como uma das referências para tal.

De certo que o conto de fadas não é a única ferramenta de intervenção a ser utilizada com crianças no enfrentamento durante o período de internação hospitalar, entretanto pode ser considerado como um importante instrumento de trabalho pela sua eficácia como função terapêutica.

\section{REFERÊNCIAS}

1. Kehl MR. A criança e seus narradores (Prefácio). In: Corso DL, Corso M. Fadas no divã: psicanálise nas histórias infantis. Porto Alegre: Artmed; 2006. p. 16.

2. Velay-Vallantin C. L'histoire des contes. Paris, Fayard, 1992. Apud Gutfreind, 2010.

3. Coelho NN. O conto de fadas, 1998. Apud Gutfreind, 2010.
4. Gutfreind C. O terapeuta e o lobo: a utilização do conto na psicoterapia da criança. Rio de Janeiro: Artes e Ofícios; 2010.

5. Corso DL, Corso M. Fadas no divã: psicanálise nas histórias infantis. Porto Alegre: Artmed; 2006.

6. Tatar M. Contos de fadas: edição comentada e ilustrada. Tradução de Maria Luiza X. de A Borges. Rio de Janeiro: Jorge Zahar; 2004.

7. Nigro M. Hospitalização: o impacto na criança, no adolescente e no psicólogo hospitalar. São Paulo: Casa do Psicólogo; 2004.

8. Chiattone HBC. A criança e a hospitalização. In: Angerami-Camon VA,

9. A psicologia no hospital. $2^{\mathrm{a}}$ ed. São Paulo: Cengage Learning; 2009. p. 23-99.

10. Bettelheim B. A psicanálise dos contos de fadas. $21^{\mathrm{a}}$ ed. Rio de Janeiro: Paz e Terra; 2008.

11. Guérin C. L'utilisation de conte chez S. Freud: l'élaboration d'um dérèglement psychique. Bulletin de Psychologie, 1981a;XXXIV(350): 515557. Apud Gutfreind, 2010.

12. Lafforgue P. Contes et thérapies, Les actes du coloque Contes et thérapies. Bordeaux: Association ailleurs; 1995b. Apud Gutfreind, 2010.

13. Radino G. Contos de fadas e a realidade psíquica: a importância da fantasia no desenvolvimento. São Paulo: Casa do Psicólogo; 2003.

14. Ferreira ABH. Novo Aurélio Século XXI. O Dicionário da Língua Portuguesa. São Paulo: Editora Nova Fronteira; 2001. p. 1225.

15. Freud S. A ocorrência, em sonhos, de material oriundo de contos de fadas (1913). In:

O caso Schreber, artigos sobre técnicas e outros trabalhos. Rio de Janeiro: Imago, 1996. v. XII. P. 301-310. (Obras Psicológicas Completas de Sigmund Freud).

16. Lafforgue P. Petit Poucet deviendra grand - Le travail du conte. Bordeaux: Mollat Editeur; 1995a. Apud Gutfreind, 2010.

17. Kaës R. Le conte et le groupe. In: Kaës R., directeur. Contes et divans. Paris: Dunod; 1996. p. 171-212. Apud Gutfreind, 2010. 
18. Araújo $A M C$ de. et al. A arte de contar histórias com o livro de folhas soltas: junto a crianças em leitos hospitalares. In: Anais do $9^{\circ}$ Congresso Nacional de Educação; 26-29 out. 2009; Curitiba, Brasil. Curitiba: PUCPR; 2009 [acesso em: 10 ago. 2011]. Disponível em: http://www. pucpr.br/eventos/educere/educere2009/anais/ pdf/1952_1419.pdf

19. Ceribelli C, Nascimento C, Pacífico SMR, Lima RAG de. A mediação de leitura como recurso de comunicação com crianças hospitalizadas. Rev. Lat. Am. Enfermagem. 2009 [acesso em 10 ago. 2011];17(1): 81-87. Disponível em: <http:// www.scielo.br/pdf/rlae/v17nl/pt_l3.pdf>.

2O. Kudo AM, Bagio M P. Introdução. O hospital pelo olhar da criança. São Caetano do Sul: Yendis Editora; 2009.

21. Neder M. Daily work in the psichological unit at a reabilitation centre: problems presented and possible solutions. Basic Services and Equipment for Rehabilitation Centre. New York, United Nations, 1967. Apud Pazinato, 2008.

22. Angerami VA. Psicologia hospitalar: a atuação do psicólogo no contexto hospitalar. São Paulo: Traço; 1984. Apud Pazinato, 2008.

23. Campos TC P Psicologia hospitalar: a atuação do psicólogo no hospital. São Paulo: EPU; 1995. Apud Pazinato, 2008.

24. Aragão RM, Azevedo MRZS. O brincar no hospital: análise de estratégias e recursos lúdicos utilizados com crianças. Estud. psicol. (Campinas, SP), 2001[acesso em 15 ago. 2011];18(3):33-42. Disponível em: http:// bases.bireme.br/cgi-bin/wxislind.exe/iah/ online/?lsisScript=iah/iah.xis\&src=google\&base= LILACS\&lang=p\&nextAction=Ink\&exprSearch=3 42398\&indexSearch=ID

25. Hanns LA. Dicionário comentado do alemão de Freud. Rio de Janeiro: Imago; 1996.

26. Spitz RA (1954), El primer año de vida del niño. Madrid: Aguilar; 1968. Apud Nigro, 2004.

27. Spitz RA. Hospitalism: an inquiry into the genesis of psuchiatric conditions in early childood (I). Psychoanal Study Child. 1954;1:53-74. Apud Chiattoni, 2009.

28. Goldenberg M. A importância da humanização no hospital: brinquedotecas terapêuticas
- Instituto Airton Senna. In: Viegas D., organizador. Brinquedoteca hospitalar: isto é humanização. Rio de Janeiro: WAK; 2007. p. 85-89.

29. Simonetti A. A terapêutica. In: Simonetti A. Manual de psicologia hospitalar: o mapa da doença. $6^{a}$ ed. São Paulo: Casa do Psicólogo; 2011. p. 115-159.

30. Lagache D., diretor. Laplanche e Pontalis: vocabulário de psicanálise. Tradução de Pedro Tamen. $4^{\mathrm{a}}$ ed. São Paulo: Martins Fontes; 2001.

31. Freud S. "Luto e Melancolia". Obras Completas, vol. XIV - Edição Standard. Rio de Janeiro: Imago; 1980. Apud Simonetti, 2011.

32. Pazinato P. Contos de fada no hospital. In: Lange ESN., organizador. Contribuições à psicologia hospitalar: desafios e paradigmas. São Paulo: Vetor; 2008. p. 295-316.

33. Corso DL, Corso M. Brincadeiras de palavras. In: As cinco idades do cérebro. Mente e Cérebro. 2009; XVI (197):46-51.

34. Winnicott DW. The concept health using instinct theory: in human nature. New York: Schocken Book; 1988. Apud Pazinato, 2008.

35. Winnicott DW. O brincar: uma exposição teórica. In: Winnicott DW. O brincar e a realidade. Rio de Janeiro: Imago; 1975.

36. Crepaldi MA. Hospitalização na infância: representações sociais da família sobre a doença e a hospitalização de sues filhos. Taubaté: Cabral Editora Universitária; 1999. Apud Nigro, 2004.

37. Safra G. Curando com histórias: a inclusão dos pais na consulta terapêutica das crianças. São Paulo: Edições Sobornost; 2005.

38. Sunderland M. O valor terapêutico de contar histórias: para as crianças: pelas crianças. Tradução Carlos Augusto Leuba Salum, Ana Lucia da Rocha Franco. São Paulo: Cutrix; 2005.

39. Winnicott DW. Objetos e fenômenos transacionais. In: Winnicott DW. O brincar e realidade. Rio de janeiro: Imago; 1975. Apud Safra, 2005. 